\title{
ANÁLISE DE DISPENSAS DE LICITAÇÕES POR CALAMIDADE PÚBLICA: UM ALERTA A PARTIR DE ESTUDOS DE CASOS *
}

\author{
Clayson Marlei Figueiredo ${ }^{1}$
}

\section{RESUMO}

As licitações públicas no Brasil, são os meios pelos quais a Administração deve realizar contratações. Esta é a regra, conforme disposição constitucional, mas em situações excepcionais, a lei 8.666/93 dispõe a possibilidade de dispensa da licitação por motivo de emergência ou de calamidade pública (Brasil, 1993). Estas possibilidades, são definidas por critérios técnicos juntamente com 0 poder discricionário da Administração. Entretanto, em casos nos quais a licitação é dispensada, a falta de técnica e/ou a má gestão dos recursos públicos, com finalidades escusas, acabam resultando em um interesse público prejudicado. Este breve estudo expõe qual o entendimento do autor sobre a postura ética que profissionais do sistema CONFEA - servidores ou do setor privado - e empresas de engenharia deveriam ter, frentes à coisa pública, focando nas contratações em eventos em que é decretado o estado de calamidade ou a situação de emergência. Analisa, a partir de exemplos, como a corrupção derivada da ausência da ética e dos preceitos morais pode prejudicar a sociedade, não só no pós desastre, mas por muito tempo, evitando a resiliência dos afetados frente aos eventos futuros. Por fim, propõem-se ações com o intuito coibir estas ações tão deletérias.

Palavras-chave: Ética; Desastre; Calamidade; Licitação; Obras e serviços de engenharia.

\footnotetext{
${ }^{1}$ Engenheiro Civil pela Universidade Federal de Juiz de Fora, Mestre em Defesa e Segurança Civil pela Universidade Federal Fluminense, Especialização em Engenharia de Petróleo e Gás pela Universidade Federal Fluminense, Especializações em Engenharia Ambiental e em Gestão de Cidades e Planejamento Urbano pela Universidade Cândido Mendes, Especialização em Evaluacón del Riesgo e Adaptación al Cambio Climático en la Costa de América Latina y Caribe, pela Universidad de Cantabria. Servidor efetivo do Município de Rio das Ostras/RJ, no cargo de Engenheiro Civil. E-mail: claysonfigueiredo@gmail.com.

* Este artigo acadêmico foi revisado e atualizado, tendo sido comunicado unicamente no IX Encontro Internacional da Rede Waterlat - Gobacit, realizado em João Pessoa/PB, de 03 a 07 de setembro de 2018 (programa disponível em www.waterlat.org/GeneralPDFs/Programa IX\%20Reunion2018.pdf), sob o título "Indústria dos Desastres: A postura ética dos profissionais e empresas de engenharia em contratos emergenciais."
} 


\title{
ANALYSIS OF BIDDING WAIVERS FOR PUBLIC CALAMITY: AN ALERT FROM CASE STUDIES
}

\begin{abstract}
Public bids in Brazil are the means by which the Administration must carry out hirings. This is the rule, according to constitutional provision, but in exceptional situations, the law $8.666 / 93$ provides for the possibility of exemption from public bidding due to emergency or public calamity. These possibilities are defined by technical criteria together with the discretionary power of the Administration. However, in cases in which the bidding is dispensed, the lack of administrative technique and / or mismanagement of public resources for obscure purposes, ends up resulting in the public interest impaired. This brief study sets out the understanding about the ethical position that professionals of the CONFEA system - servers or of the private sector - and engineering companies should have in front of the public thing, focusing on the contracting in events in which is decreed the emergency situation or the state of calamity. It examines, from examples, how corruption derived from the absence of ethics and moral precepts can harm society, not only in post-disaster, but for a long time, avoiding the resilience of those affected in the face of future events. Finally, actions are proposed with the intention of curbing these actions so deleterious.
\end{abstract}

Keywords: Ethics; Disaster; Calamity; Bidding; Buildings and engineering services. 


\section{INTRODUÇÃO}

O Código de Ética dos profissionais do sistema CONFEA ratifica a função social destes, abrangendo a promoção da segurança, da qualidade de vida, da sustentabilidade, da proteção aos valores mais caros da experiência profissional. Para cumprir esses objetivos, a busca por uma padronização da conduta profissional determina que cada um dos elos que compõem essa cadeia conduza suas atividades seguindo os princípios da ética, parte da filosofia que se preocupa com a evolução da humanidade. Essa busca é renovada diariamente, estabelecendo um vínculo inalienável entre a sociedade e o exercício profissional. O relacionamento profissional, a intervenção sobre o meio, os deveres, os direitos, a honradez e a eficácia são perspectivas pautadas neste conceito moral. Sob a égide da ética, interesses pessoais e comuns são compulsoriamente identificados com as necessidades da sociedade. Ela exige que nos preocupemos em apontar soluções tecnológicas de interesse social e humano, principal característica dessa função moral embasada na ciência do dever e da obrigação, a para a construção de um mundo mais justo, fraterno e sustentável para todos.

O objetivo das profissões e da ação dos profissionais é o bem-estar e o desenvolvimento do homem, em seu ambiente e em suas diversas dimensões: como indivíduo, família, comunidade, sociedade, nação e humanidade; nas suas raízes históricas, nas gerações atual e futura. A profissão é bem social da humanidade e o profissional é o agente capaz de exercê-la, tendo como objetivos maiores a preservação e o desenvolvimento harmônico do ser humano, de seu ambiente e de seus valores. A profissão também é bem cultural da humanidade, construído permanentemente pelos conhecimentos técnicos e científicos, manifestando-se pela prática tecnológica, colocado a serviço da melhoria da qualidade de vida do homem. A profissão é alto título de honra e sua prática exige conduta honesta, digna e cidadã. Realiza-se pelo 
cumprimento responsável e competente dos compromissos profissionais, munindo-se de técnicas adequadas, assegurando os resultados propostos e a qualidade satisfatória nos serviços e produtos e observando a segurança nos seus procedimentos. A profissão é praticada através do relacionamento honesto, justo e com espírito progressista dos profissionais para com os gestores, ordenadores, destinatários, beneficiários e colaboradores de seus serviços, com igualdade de tratamento entre os profissionais e com lealdade na competição. É exercida com base nos preceitos do desenvolvimento sustentável na intervenção sobre os ambientes natural e construído, e na incolumidade das pessoas, de seus bens e de seus valores (CONFEA, 2019).

O princípio da moralidade é trazido pela Constituição Federal, em seu artigo 37, caput, ao lado da legalidade, impessoalidade, moralidade, publicidade e eficiência. No entanto, conforme salienta Mello (2014, p.98), temse que este rol de princípios não é exaustivo, pois inúmeros outros merecem igualmente consagração constitucional: uns, por constarem expressamente na Lei Maior, conquanto não mencionados no art. 37, caput; outros, por nele estarem abrangidos logicamente, isto é, como consequência irrefragáveis dos aludidos princípios; e ainda outros, finalmente, por serem implicações evidentes do próprio Estado de Direito e, pois, do sistema constitucional como um todo.

Neste particular, o princípio da moralidade abarca um ramo de compreensão da moral na administração além dos meros ditames legais. Tal princípio alude à própria ética do administrador, definindo que este, no exercício de sua função pública, não se abstenha da aplicação dos preceitos éticos na sua lida com o que é público (CARVALHO FILHO, 2013, p. 21). Entende-se que todos aqueles que lidam com o bem público deve não só averiguar os critérios de conveniência, oportunidade e justiça em suas ações, mas também distinguir o que é honesto do que é desonesto.

Numa visão global, a Administração é, todo o aparelho o preordenado à realização de serviços, visando a satisfação das necessidades coletivas. 
Meirelles (2008), neste entendimento, quando se fala em imoralidade na administração pública, fala-se em, muitas vezes, no não atendimento à essas necessidades coletivas, ou seja, em prejuízo à coletividade. Diversos podem ser os prejuízos causados pela falta de ética nas dispensas de licitações, pois, em muitas situações os atos de imoralidade administrativa tornam-se, também, em atos de improbidade administrativa, os quais terminam por causar prejuízo ao erário, aos cofres públicos. (CARVALHO FILHO, 2013, p. 22).

Neste mesmo viés, para Figueiredo (2004, p.459) a licitação é o procedimento administrativo formal, nominado, cuja finalidade é selecionar o melhor contratante para a Administração, que the deverá prestar serviços, construir-Ihe obras, fornecer-Ihe ou adquirir-Ihe bens. Sendo assim, o caráter técnico e objetivo dos critérios de definição e constatação das situações de emergência ou de calamidade pública, deve ser plenamente claro, ensejando assim a dispensa do procedimento licitatório, sendo de extrema importância considerar o que se estabelece como requisitos para a elucidação correta destas decretações, verificando ainda se: a) a tal situação adversa, não se tenha originado, total ou parcialmente, da falta de planejamento, da desídia administrativa ou da má gestão dos recursos, sem que possa, ser atribuída à culpa ou dolo do agente público que tinha o dever de agir para prevenir a ocorrência; b) a existência de urgência concreta e efetiva do atendimento à situação decorrente do estado emergencial ou calamitoso, visando afastar risco de danos aos bens, à saúde ou à vida de pessoas; c) o risco, além de concreto e efetivamente provável, se mostre iminente e especialmente gravoso; d) a imediata efetivação, por meio de contratação com terceiro, de determinadas obras, serviços ou compras, segundo as especificações e quantitativos tecnicamente apurados, seja o meio adequado, efetivo e eficiente para afastar o risco iminente detectado. (GASPARINI, 2014, p.587).

Nota-se então, que a ética e a moralidade pública prescindem não somente da obediência irrestrita aos seus preceitos legais, mas também, muito além disso, da obediência às "regras não-escritas da Administração". 
(OSÓRIO, 2007, p. 92). Muito embora o agente público (ou o licitante) deva fazer apenas o que está previsto em lei, há momentos em que a própria lei o faculta a possibilidade de escolha, o chamado poder discricionário. Contudo, na esfera das licitações públicas, este é o campo no qual existe maior propensão aos atos imorais, podendo ocorrer que a solução escolhida pela autoridade, embora permitida pela lei, contrarie valores éticos não protegidos pela regra jurídica, mas passíveis de proteção por estarem subjacentes em determinada coletividade. (DI PIETRO, 2007, p.161).

A ética é alcançar a ideia de boa-fé e lealdade para a gestão da coisa pública, da atuação moral, impedindo que a Administração atue frente ao administrado de forma astuciosa, desleal, agindo de modo a impedir o exercício dos direitos por parte dos cidadãos (MELLO, 2008, p. 120).

\section{MATERIAIS E MÉTODOS}

Ao observarmos o contexto de ocorrência de desastres no Brasil, vemos que as autoridades nomeiam como 'naturais' a sua quase totalidade (mais de 90\%). O foco das explicações institucionais sobre os desastres acontecidos recai sobre as especificidades do evento - no geral, de origem hidrometeorológica - até concluir que se tratou de um perigo inusitado. É dessa explicação que se extrai a justificativa institucional para não se estar adequadamente preparado nem ter promovido a preparação comunitária devida, associando-se à ideia de que só restaria lidar com uma parcela das consequências (perdas e danos), no geral, movimentando a indústria do desastre (VALENCIO, 2014a).

Este estudo faz uma abordagem usando um método de pesquisa 0 dedutivo, sendo que as pesquisas utilizadas foram tipo qualitativa, teórica com uso de material bibliográfico e documental-legal. 


\section{RESULTADOS E DISCUSSÃO}

No decênio 2004-2013, foi preocupante tanto a evolução dos atos administrativos de decretação municipal de situação de emergência (SE) e de estado de calamidade pública (ECP) no país, reconhecidos pelo ente federal através de portaria emitida pela Secretaria Nacional de Defesa Civil do Ministério da Integração Nacional (SEDEC/MI), quanto a sua média anual. Durante a primeira gestão do presidente Lula (2003 - 2006), o percentual anual de decretações municipais de emergência (SE e ECP) em relação ao total dos municípios brasileiros foi de $21,25 \%$. Na segunda gestão de Lula (2007 - 2010), foi de 22,75\%. Já na primeira gestão da presidente Dilma, (2011 - 2014), em média, anualmente, $31,56 \%$ dos municípios brasileiros declarou emergência. Somente durante o último governo (2015 - 2018), estes números recuaram um pouco para $28,32 \%$ (BRASIL, 2020). Em média, no país e a cada ano, $1 / 3$ das decretações de emergência se repetem ou se estendem temporalmente no mesmo município. Isso indica que as autoridades locais não conseguiram equacionar o problema, ainda que com o auxílio dos níveis superiores de governo estadual e federal. A figura a seguir representa um gráfico compilado pelo autor com os dados citados. 
Figura 1 - Decretações de Situação de Emergência e Estado de Calamidade Pública expedida aos municípios brasileiros pelo governo federal, durante os últimos mandatos presidenciais.

\section{Municípios que decretaram SE ou ECP}

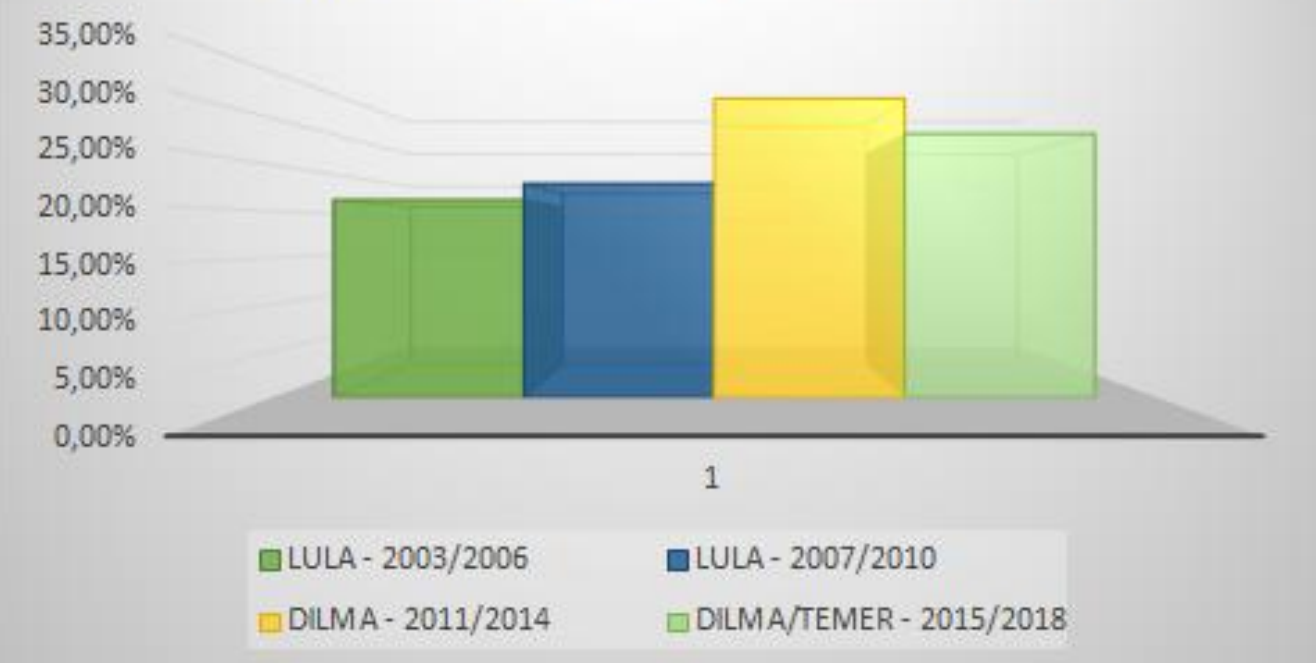

Fonte: Dados do S2ID, gráfico elaborado pelo autor.

O Município de Sítio Novo/RN, sob a justificativa de situação de calamidade pública na área rural, contratou sem licitação uma empresa para assumir a obra, orçada em $\mathrm{R} \$ 946,3$ mil. As investigações mostraram que os sócios da empresa eram uma empregada doméstica desempregada e um agricultor que sustenta a família com renda vinda do trabalho na roça (ROSÁRIO, 2013).

Uma das três maiores empresas do país, com negócios, inicialmente concentrados nos estados do Nordeste, atua hoje em todo o território nacional e no exterior. Inicialmente uma construtora, ao longo das últimas décadas veio a atuar também em obras de estaleiros, construção de hidrelétricas, aeroportos, portos, submarinos, empreendimentos imobiliários, exploração de petróleo e administração de estradas e aeroportos. Com a experiência e a tecnologia adquirida, o grupo passou a ocupar um papel central nos projetos estatais de desenvolvimento e defesa nacional. Com receitas anuais de dezenas de bilhões de reais, teve seu envolvimento em relações escusas deflagradas nas investigações da "Operação Lava-Jato" (GASPAR, 2016). A 
jornalista Malu Gaspar chama atenção para que a relação dessas empreiteiras, mais do que a engenharia, é firmar e gerenciar seus laços com os governos, não importa de que cor ideológica.

$\mathrm{Na}$ casa de um dos diretores da empresa foram apreendidas "minutas de ofício" manuscritas, que tratam de pedidos de liberação de recursos para obras, e também de convite para que a própria empresa realize uma obra em caráter emergencial. A primeira minuta é identificada como do Governador do Amapá para a Ministra da Ação Social. $O$ texto começa fazendo referência à disseminação da cólera no estado do Amapá: "Diante das características catastróficas e epidêmicas", com o registro inclusive de óbitos, a ministra é informada da decretação pelo governo estadual do "Estado de Calamidade Pública". Após o relato da situação, é feito o "pedido": A contratação das obras de ampliação e melhoria de abastecimento de águas da cidade de Santana AP. Ao final do que conclui: "Diante do exposto, solicito a V. Exa. que, utilizando-se da faculdade contida no item 16 da Resolução $n^{\circ} 25$ do Conselho Curador do FGTS, gestione junto àquele órgão para o atendimento em caráter excepcional, (...) da contratação das obras (...) como medida preventiva do alastramento da moléstia". Duas outras minutas de ofícios referindo-se também a ameaças de disseminação da cólera no estado de Rondônia foram encontradas na residência do diretor. Os dois documentos manuscritos, tratam da realização de obras de saneamento pela Companhia de Águas e Esgoto do Estado de Rondônia (CAERD). Esses dois últimos documentos, evidenciam o lugar do uso da necessidade das populações para justificar os pedidos de obras, a participação da empresa na elaboração de esboços de documentos oficiais e a coordenação pela empresa de decisões da administração pública relativas a obras de seu interesse, o que inclui, aparentemente, a elaboração de um convite para ela mesma realizar a obra. $O$ entrelaçamento entre a atuação da empresa e as práticas políticas pode ser especialmente observado na participação que têm os parlamentares tanto na elaboração quanto na execução do orçamento (BEZERRA, 2017). 
Revista Científica do Corpo de Bombeiros Militar de Pernambuco

Artigo Publicado no Vol.07 N.20 - Edição Especial 2021 - ISSN 2359-4829

Versão on-line disponível em: http://www.revistaflammae.com

O pior desastre de origem natural que se tem registro no Brasil aconteceu em janeiro de 2011 quando intensas chuvas atingiram a Região Serrana do Rio de Janeiro causando inundações e deslizamentos. A cidade de Teresópolis e seis outros municípios da região tiveram subsequentemente decretado o estado de calamidade pública, uma condição legal para a recepção de recursos estaduais e federais (RAPOSO, 2016). Seis meses após o desastre ter ocorrido uma investigação foi aberta pelo Ministério Público Federal a partir da delação do executivo de uma companhia privada revelando um esquema de corrupção na contratação de serviços de reconstrução por meio do pagamento de propina que chegava a representar até $50 \%$ do valor dos contratos (TCE-RJ, 2011). A mídia local também revelou o paradoxo de haver serviços não iniciados ou incompletos e de localidades severamente afetadas ainda não atendidas vários meses depois do evento em que pese os significativos montantes de recursos que foram disponibilizados por diferentes fontes tanto públicas quanto privadas.

Figura 2: Imagens de cidades da Região Serrana Fluminense, logo após desastre ocorrido em 2011.
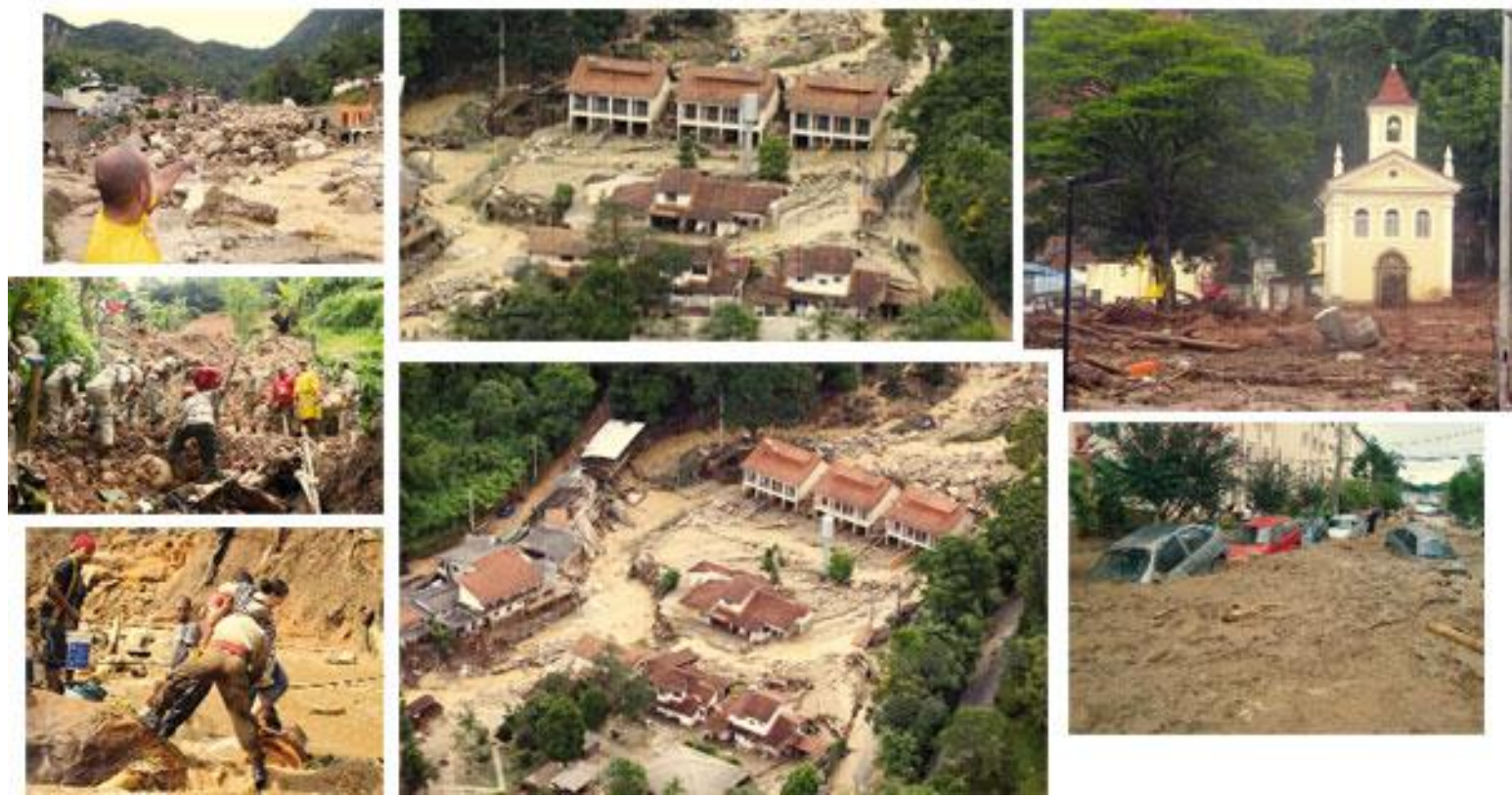

Fonte: Folha do Meio Ambiente (http://www.folhadomeio.com.br/fma_nova/noticia.php?id=2981). 
O Tribunal de Contas do Estado, concluiu que havia forte evidência que gestores públicos, utilizando-se da oportunidade do estado de calamidade na região, "se utilizaram de mecanismos para se locupletarem com a desgraça alheia" e apontou, como irregularidades cometidas: a fraude na utilização do dinheiro público, obras inacabadas, a malversação de verbas, a utilização inadequada de suprimentos, a celebração de contratos verbais, de contratos sem licitação acima dos valores de mercado e sem a formalização de atos de dispensa de licitação com empresas que realizaram ações emergenciais após a tragédia, além da falta de controle na execução contratual" (TCE-RJ, 2011).

\section{CONCLUSÕES}

A falta de ética e a corrupção é, por sua própria natureza de dissimulação, uma espécie de "arranjo de portas fechadas" e, portanto, a participação é necessariamente restrita. De fato, pode-se argumentar que seja a antítese do processo de participação ampla, democrática e transparente almejada por um bom processo de governança em desastres uma vez que prioriza o atendimento de interesses particulares daqueles envolvidos em atos de corrupção em detrimento da satisfação dos legítimos interesses dos grupos atingidos que ficam excluídos do processo. Tal fato parece ter ocorrido em ambos os casos estudados nos quais a eficácia e a eficiência das medidas de precaução e recuperação não corresponderam ao que era esperado tendo em consideração a vasta soma de recursos disponibilizados.

Ainda mais importante, todavia, pode ser o fato que se os recursos não são aplicados na intenção de atendimento aos grupos afetados, mas no intuito do ganho próprio, esta lacuna pode afetar diretamente a resiliência destes grupos frente a possíveis eventos futuros do mesmo gênero uma vez que os efeitos das medidas de resposta e reconstrução ficam comprometidos ou diminuídos por conta da corrupção, o que viria a perpetuar a vulnerabilidade dos grupos quando, por exemplo, uma obra de engenharia não é feita. 
De acordo com os casos estudados, um efeito perverso da corrupção quando esta aflige a governança de desastres é o fato que seus efeitos podem permanecer por longo tempo após a ocorrência do desastre em si. A corrupção foi vista como perpetuadora da exposição de comunidades afetadas ao risco devido à falta de diligência no processo de resposta e reconstrução, afetados pelo desvio de finalidade na gestão dos recursos destinados à recuperação. A relação entre corrupção e vulnerabilidade pode ser considerada como uma forma de "vulnerabilidade delinquente". Tierney (2012) considera existir uma associação entre corrupção e vulnerabilidade a desastres, sendo a primeira uma forma de déficit de governança que vem a impactar a segunda.

Quanto ao procedimento licitatório Rosa (2003, p.8) também afirma que o Princípio da Publicidade se aplica a todas as fases do procedimento licitatório. Destarte, para a perfeita transparência do certame, dever-se-á dar publicidade de todos os atos do procedimento, desde a disponibilização do edital de abertura, avisos, anexos, análise de documentação e propostas, até a homologação e contratação, sem prejuízo da disponibilização, a qualquer interessado legitimado de todo o processo para apreciação da legalidade. E edifica que todos os atos do procedimento deverão ser levados ao conhecimento público e, em especial, a todos os participantes. O princípio incide desde a abertura do certame até a contratação.

A fim de combater a corrupção, a transparência é tida como sendo peçachave no controle de comportamentos abusivos e, uma vez disponível, em permitir a sociedade civil de agir como um valoroso aliado na prevenção da corrupção e na guarda da alocação da ajuda disponibilizada nas verdadeiras necessidades. A transparência pode ser alcançada por diversos meios e sua adoção pode depender dos meios e das capacidades das instituições locais das áreas afetadas. 


\section{REFERÊNCIAS}

BEZERRA, M. O. Corrupção e produção do Estado. Revista Pós Ciências Sociais, v. 14, n. 27, p. 99-130, 2017.

BRASIL. Lei Federal n. 8.666, de 21 de Junho de 1993. Regulamenta o art. 37, inciso XXI, da Constituição Federal. Disponível em: http://www.planalto.gov.br/ccivil_03/leis//8666cons.htm> Acessado em 02 de junho de 2021.

BRASIL. Ministério do Desenvolvimento Regional, Secretaria Nacional de Proteção e Defesa Civil. Sistema Integrado de Informações sobre Desastres - S2ID. Disponível em https://s2id.mi.gov.br/paginas/relatorios. Acessado em 01 de junho de 2021.

CARVALHO FILHO, J. S. Manual de Direito Administrativo. 26. ed. São Paulo: Atlas, 2013.

CONFEA - Conselho Federal de Engenharia e Agronomia. Código de Ética Profissional da Engenharia, da Agronomia, da Geologia, da Geografia e da Mereologia. 11 $11^{\underline{a}}$ edição, Brasília, 2019. Disponível em: https://www.confea.org.br/sites/default/files/uploadsimce/CodEtica11ed1_com_capas_no_indd.pdf. Acessado em 03 de junho de 2021.

DI PIETRO, M. S. Z. Discricionariedade Administrativa na Constituição de 1988. 2. ed. São Paulo: Atlas, 2007.

GASPARINI, D. Direito Administrativo. 17. ed. São Paulo: Saraiva 2014. 54.

MEIRELLES, H. L. Direito Administrativo Brasileiro. 34. ed. São Paulo: Malheiros, 2008. 
MELLO, C. A. B. de. Curso de Direito Administrativo. 25a Ed. Revista e atualizada até a Emenda Constitucional 56, de 10.12.2007 - $2^{\mathrm{a}}$ tiragem. São Paulo: Malheiros, 2008.

MELLO, C. A. B. de. Curso de Direito Administrativo. 31. ed. São Paulo: Malheiros, 2014.

RAPOSO, L. C. M. M. M. Desastres políticos após desastres naturais: uma análise comparativa da governança em desastres entre as cidades de Teresópolis- Brasil e Áquila- Itália. I Congresso Brasileiro de Redução de Riscos de Desastres. Paraná, 2016.

ROSA, M. F. E. Direito Administrativo. 5ª ed. São Paulo: Editora Saraiva, 2003.

ROSÁRIO, W. C. Fraudes em Licitação. PNLD - Programa Nacional de Capacitação e Treinamento para o Combate à Corrupção e à Lavagem de Dinheiro. CGU/SFC/GSGAB. 2013. Disponível em http://www.atricon.org.br/wpcontent/uploads/2013/09/PNLD_Fraudes_26.09.pdf. Acessado em 03 de junho de 2021.

TIERNEY, K. Disaster Governance: Social, Political, and Economic Dimensions. Annu. Rev. Environ. Resour. 37, 2012, pp. 341-363.

TCE/RJ - Tribunal de Contas do Estado do Rio de Janeiro, Relatório de Auditoria Governamental Processo 215.638-1/11, Rio de Janeiro, 2011, p. 190. Disponível em: http://www.senado.leg.br/comissoes/documentos/SSCEPI/Vega0738\%20\%2003\%20-\%20Afastamentos\%20Prefeitos.pdf. Acessado em 01 de junho de 2021.

VALENCIO, N. "Desastres, tecnicismo e sofrimento social". Ciência \& Saúde Coletiva, Rio de Janeiro, v. 19, n. 9, 2014a, p. 3631-3644. 